* Pós-doutor pela Universidade de Granada - Espanha. Doutor em Direito pela Universidade Federal de Santa Catarina. Mestre em Direito pela Universidade Federal de Santa Catarina Possui graduação em Direito pela Universidade Federal de Santa Maria. Professor permanente da Universidade Federal de Santa Catarina. E-mail: luiz.cademartori@ gmail.com.

** Doutoranda em Direito pela Universidade Federal de Santa Catarina. Mestre em Direito pela Universidade Federal de Santa Catarina. Especialização em Direito Penal, Processo Penal e Criminologia pela Faculdade União e Instituto Busato de Ensino. Professora substituta da Universidade Federal de Santa Catarina. E-mail: camargopriscilla@gmail.com.

*** Graduado no curso de Filosofia (bacharel e licenciatura) pela Universidade Federal de Santa Catarina. Graduando na $9^{\mathrm{a}}$ fase do curso de Direito pela mesma instituição. Pesquisador pelo $\mathrm{CNPq} / \mathrm{PIBIC}$ há três anos. E-mail: rfaresin@yahoo. com.br.

\section{A Constituição Brasileira como produto de terceira geração: convergências e divergências entre o constitucionalismo latino americano e a teoria do garantismo jurídico}

\author{
The Brazilian Constitution as third \\ GENERATION PRODUCT: CONVERGENCE AND \\ DIFFERENCES BETWEEN THE LATIN AMERICAN \\ CONSTITUTIONALISM AND LEGAL GARANTISM \\ THEORY
}

* Luiz Henrique Urquhart Cademartori ** Priscilla Camargo Santos *** Rodrigo Adriano Faresin

Resumo: Este trabalho tem como objetivo abordar o fenômeno do constitucionalismo latino americano, suas características e pontos críticos frente aos modelos constitucionalistas europeus tais como os do garantismo jurídico e o neoconstitucionalismo. Assim, o trabalho contrapõe as recentes propostas teóricas no âmbito da teoria constitucional latino americana com a tradição europeia. Desta forma, delimitam-se os principais institutos do constitucionalismo latino e se faz o cotejamento entre as teorias latino americanas e europeias sobre a Constituição, tais como os estudos garantistas de Ferrajoli e de representantes do neoconstitucionalismo como Dworkin, Alexy, Müller e Häberle. Busca-se entender e explicitar as chamadas "constituições de terceira geração", para melhor conceber o constitucionalismo brasileiro e o impacto dos novos institutos jurídicos e garantias processuais que a nossa Constituição assegura para viabilizar os direitos fundamentais e sociais. Em um segundo momento é investigado as possíveis convergências que o constitucionalismo latino americano encontrou na teoria do garantismo jurídico que, embora de origem europeia, encontrou ampla recepção no modelo dogmático constitucional de países como Brasil ao criar garantias de efetivação dos direitos sociais.

Palavras-chave: Constituições de terceira geração. Neoconstitucionalismo. Garantismo.

Abstract: This article addresses the phenomenon of the latinamerican constitutionalism, its characteristics, critical issues 
and its challenges facing the European constitutional models, such as the legal garantism and neoconstitutionalism. That being said, this work compares the recent theoretical proposals within the Latin American constitutional theory with the European tradition. In this way, we delimit the aspects of main Latin American constitutionalism theory and contrast European constitutional theories, such as Ferrajoli's legal garantism and representatives of neoconstitutionalism such as Dworkin, Alexy, Müller and Haberle. In this work, we seek to understand and explain the so-called "third generation constitutions", in order to think properly of the Brazilian constitutionalism and the influence of the new legal institutions and procedural safeguards contained in our Constitution which give means to make possible fundamental and social rights. After that, we examine the affinities that Latin American constitutionalism has found in the legal garantism theory, which enables fundamental and social rights, and which has been largely accepted in countries similar to Brazil despite of its European origins.

Keywords: Third-generation constitutions. Neoconstitutionalism. Legal garantism. 


\section{INTRODUÇÃO}

No atual modelo político e jurídico estatal, centrado na figura do Estado Constitucional de Direito, ganha relevo a discussão acerca das formas de se interpretar e aplicar as normas constitucionais, notadamente os direitos fundamentais, campo de investigação de extrema importância para o constitucionalismo contemporâneo. De fato, com a crise paradigmática da epistemologia positivista (e seu método científico de interpretação e fundamentação normativas, sob premissas lógico-formais e analíticas), consagradas na versão de jusfilósofos tais como Herbert Hart, no contexto anglo-saxão, e Hans Kelsen, no âmbito continental europeu, teve como desdobramentos posteriores uma epistemologia pós-positivista, cuja pretensão é a recuperação da dimensão ética do discurso jurídico e o equacionamento entre as dimensões do Direito, da Moral e da Política.

Essa revisão hermenêutica, ainda acarretou desdobramentos tais como o ativismo judiciário, a principiologia constitucional como método ideal de incidência dos direitos fundamentais, via ponderação de princípios, e mais recentemente, a polêmica entre essa nova concepção de Direito, resultante de todo esse fenômeno, chamada Neoconstitucionalismo e seus aspectos críticos apontados pela Teoria do Garantismo Jurídico.

Com base nessas premissas e ainda, no atual quadro das chamadas Constituições de Terceira Geração, estas constituições são caracterizadas por serem extensas, por possuírem um elevado grau de rigidez, por uma multiplicação dos direitos fundamentais nelas estabelecidos, por um desenvolvimento das funções e das instituições de garantia, tal como são apontadas em algumas das novas constituições latino-americanas, tais como as de Bolívia, Equador, e também a do Brasil, por autores como Ferrajoli. Assim pretendeu-se neste estudo, realizar um questionamento crítico a esse fenômeno, situando mais detidamente a análise na Constituição do Brasil e seus desdobramentos políticos, jurídicos e institucionais que dela emanam.

Para tanto, primeiramente foi traçado um panorama geral sobre as recentes teorias advindas da Europa e Estados Unidos tais como o Neoconstitucionalismo, (este concebido, mais como uma aglutinação nem sempre convergente de novas teorias hermenêuticas e argumentativas do Direito), o Garantismo Jurídico, cujo expoente e principal polemizador é Luigi Ferrajoli e a Teoria da Integridade defendida pelo norte americano Ronald Dworkin. 
A seguir, se contextualizou essas teorias diante das respostas críticas do movimento conhecido como Constitucionalismo Latino Americano, onde foi dado um enfoque mais detido ao modelo constitucional do Brasil, bem como um resumo do atual debate sobre os problemas políticos, institucionais e jurídicos brasileiros, segundo alguns dos seus principais representantes no campo da Teoria do Direito.

Como desfecho, traçou-se um enfoque sobre as principais características das chamadas Constituições de Terceira Geração, conforme definidas por Luigi Ferrajoli (2010), partindo-se das críticas Garantistas ao Neoconstitucionalismo. Assim, foram apontadas algumas das principais incongruências entre o modelo dogmático constitucional prescrito na Constituição Federal do Brasil, como exemplo de Constituição de Terceira Geração, e as atuais práticas governamentais, notadamente anti-garantistas, que ainda dificultam a consolidação de um projeto efetivamente emancipatório para a realidade constitucional brasileira.

\section{A CONSOLIDAÇÃO DO ESTADO CONSTITUCIONAL DE DIREITO E SEUS DESDOBRAMENTOS NO ÂMBITO DA HERMENÊUTICA CONSTITUCIONAL}

Historicamente, pode-se situar uma gradativa mutação da organização jurídico-política dos Estados europeus, que transita pelo Estado Liberal de Direito, do século XIX, passa pelo Estado Social de Direito do pós-guerra no século XX, até chegar ao Estado Constitucional de Direito caracterizando o atual contexto jus-político e social (STRECK, 1999, p. 36). Inicialmente, o Estado Liberal de Direito (consolidado a partir das revoluções burguesas, tais como a Revoluções Francesa e Americana, no século XVIII) institucionalizou o triunfo da burguesia comerciária sobre as elites aristocratas do Antigo Regime, momento em que o Estado adquiriu feições abstencionistas, de prestação negativa, isto é, deixando livres as forças econômicas para se auto-organizarem, adotando então a posição de mera polícia da sociedade civil, garantidora exclusivamente das liberdades individuais, vale dizer, dos direitos fundamentais de primeira dimensão. Esta era a exigência do capitalismo emergente, período que se prolongou até o final da primeira grande guerra. Neste período, o normativismo positivista de Hans Kelsen (1999) preponderou como teoria jurídica hegemônica, quando o desvirtuamento de sua teoria resultou na equiparação entre Direito e lei, ou Direito e norma. 
O Estado Social de Direito, por seu turno, formalizou o capitalismo maduro, no qual se abdicou do abstencionismo, inaugurando-se um período de intervencionismo nas relações econômicas da sociedade civil, de modo que estas prestações positivas estatais converteram-se em elemento crucial na produção e distribuição dos bens do capital. Assim programou-se uma agenda de compromissos com direitos sociais como segundo rol de normas constitucionais, também chamados direitos fundamentais de segunda dimensão.

Com o advento do Estado Social de Direito, fruto do fenômeno acima mencionado, após as atrocidades da segunda grande guerra, o constitucionalismo europeu sofreu, também, uma virada hermenêutica. Este movimento teórico ficou conhecido, segundo alguns autores, como nova hermenêutica constitucional, em boa medida incorporada nas teses centrais do Neoconstitucionalismo. ${ }^{1}$

Visando a retomada do Direito pela guarida constitucional, assegurandose que o Direito, antes de ser apenas norma ou apenas lei, é também valor, o Neoconstitucionalismo apregoou a vigência imperativa do princípio-síntese da dignidade da pessoa humana, sustentáculo ético do projeto político das novas Cartas Políticas europeias.

Neste processo de constitucionalização do Direito, alguns embates teóricos e filosóficos ganharam relevância. De início, no debate havido entre Ferdinand Lassalle ${ }^{2}$ e Konrad Hesse ${ }^{3}$, acerca da força normativa da Constituição, prevaleceu a tese do segundo, para quem o texto normativo da Constituição, seu documento jurídico, possui uma força normativa que the é inerente e que prepondera no choque com a realidade fática das relações reais de poder da sociedade, funcionando como fator e produto destas relações. Ao

\footnotetext{
O significado de neoconstitucionalismo diz respeito a um novo modelo de organização jurídicopolítica do Estado de Direito, bem como ao tipo de teoria do direito necessária para que se explique e fundamente tal concepção de Estado. Pode-se, inclusive, tratar o neoconstitucionalismo como ideologia, com a qual se impõe uma nova forma de encarar a Constituição. Segundo Pérez Luño, o que difere o Estado Liberal Clássico do que ele denomina de Estado Constitucional é um tríplice deslocamento do papel das normas constitucionais e infraconstitucionais, a saber: a) deslocamento do princípio da primazia da lei para o princípio da primazia da Constituição; b) deslocamento da reserva da lei à reserva constitucional; c) deslocamento do controle jurisdicional da legalidade ao controle jurisdicional da constitucionalidade. (CADEMARTORI; DUARTE, 2009, p. 31).

2 Ferdinand Lassalle afirmou que a essência da Constituição trata exclusivamente de questões políticas, ao expressar as relações de poder dominantes no país. Estas relações fáticas constituiriam a força ativa que determinaria o sentido das leis e das instituições da sociedade, sendo a correlação de forças resultante dos fatores reais de poder (poder militar das Forças Armadas, poder econômico das indústrias e do capital, poder intelectual, etc.). Neste sentido, o documento denominado Constituição, nas palavras de Lassale, seria apenas um pedaço de papel. (LASSALLE, 1980).

3 Para Hesse, a essência da norma constitucional reside na sua própria vigência, sua pretensão de eficácia, que não pode ser desvinculada dos condicionantes históricos, políticos, econômicos de sua realização, justamente os fatores que lhe deram vazão. (HESSE, 1991).
} 
mesmo tempo em que emergiria dessa disputa, a Constituição seria capaz de conformá-la, imprimindo-lhe uma ordem determinada.

Por outra parte, na seara do mundo jurídico, o movimento teórico determinante a respeito do estatuto da Constituição, foi o desencadeado por Hans Kelsen e Carl Schmitt, - notadamente, sobre quem deveria ser o intérprete da constituição, em uma famosa polêmica na década de trinta do século passado, a qual delimitou um marco histórico decisivo sobre as concepções a respeito do papel da Constituição, face à interpretação e aplicação das suas normas, no restante do século XX e ainda hoje no século XXI.

As razões dessa constatação derivam de uma parte, do contexto histórico e sócio- político onde tal discussão se desenvolveu, ou seja, a partir da crise do paradigma do Estado Liberal e o conseqüente advento do Estado Social de Direito, consagrado nas constituições dirigentes do México (1917) e da República de Weimar (1919) constituindo esta última o marco jurídicopolítico onde se assenta o debate. De outra parte, tais autores desencadearam o que teriam sido as verdadeiras e autênticas concepções alternativas das constituições democráticas do século XX. Além do mais, isto também gerou, a partir da mesma época, toda uma corrente constitucionalista centrada no problema da normatização e auferimento de densidade regulativa aos Direitos Fundamentais. Tal empreitada compreendeu não somente os originários direitos de liberdade, mas igualmente direitos sociais, políticos, econômicos e cívicos.

Contudo, não obstante sua importância, grande parte das problematizações teóricas sobre tais Direitos, ao afirmar genericamente sua universalidade e necessária efetivação, subestimam suas múltiplas dimensões e complexidades temáticas, ao deixar de analisar-se o caráter ideológico, político, social, econômico e cultural que decorre do seu enfoque normativo de direitos constitucionalmente positivados.

Diante desse contexto, alguns autores, a partir da década de setenta do século passado, passaram a refletir a partir de teorias próprias, novas formas de conferir aplicabilidade efetiva aos direitos fundamentais, em todas as suas dimensões. É o caso de Friedrich Müller (1991), que construiu sua teoria preceituando que a força normativa não se efetiva com a mera emissão de um dado texto legal, pois este é apenas parte componente de um fenômeno maior. Em linhas gerais, Friedrich Müller propõe uma teoria jurídica estruturante do direito constitucional. Em sua orientação os problemas relacionados aos processos decisórios, inseridos na atual hermenêutica constitucional, não devem 
ser solucionados a partir de uma interpretação da norma, mas sim de uma tarefa de concretização do seu sentido.

Para estruturar sua teoria o autor aponta, primeiramente, que a norma jurídica não se confunde com o seu texto, portanto ressalta uma não identidade do texto da norma e a norma propriamente dita. Tal diferenciação tem como ponto de partida a ideia de que a norma oferece diversas possibilidades de compreensão que não estão inseridas em seu texto.

Assim, o texto da norma não contém a normatividade e a sua estrutura material concreta. Os conceitos jurídicos apresentados nos textos das normas, quando só considerada sua concepção literal, não possuem significado e os enunciados não possuem sentido. A norma jurídica não se apresenta pronta, nem substancialmente concluída, esse processo se dará, exatamente, com a concretização. (MÜLLER, 2000).

Compreendido que a norma não se confunde com seu texto, deve-se delinear a norma jurídica, que para o autor, é composta por dois elementos: o programa da norma e o âmbito da norma. O programa normativo corresponde ao teor literal da lei, ao seu enunciado propriamente dito. Já o âmbito da norma "é o recorte da realidade social na sua estrutura básica, que o programa da norma escolheu para si ou em parte criou para si como seu âmbito de regulamentação." (MÜLLER, 2000, p. 57).

Dessa forma, a estrutura da norma resulta da implicação recíproca desses dois elementos, programa normativo e âmbito da norma, os quais devem ser aproximados em sentidos recíprocos e tendo como critérios de aproximação, os clássicos cânones da interpretação constitucional, quais sejam: histórico, teleológico, sistêmico e gramatical. ${ }^{4}$

Por outra parte, outro jurista que veio apresentar proposta diversa do constitucionalismo clássico para dar conta da nova empreitada de efetivação dos direitos fundamentais no seu todo, foi Peter Häberle, o qual erigiu sua hermenêutica constitucional, postulando uma sociedade aberta dos livres intérpretes da Constituição, a qual estabelece que, no processo de formação da força normativa da Constituição, estariam potencialmente envolvidos todos os indivíduos de uma sociedade. ${ }^{5}$ No caso deste autor, o que se vislumbra na sua

\footnotetext{
${ }^{4}$ Müller apresenta um novo conceito de norma, compreendendo-a como uma estrutura dividida entre programa normativo (o texto/enunciado da norma, seus elementos lingüísticos), e o âmbito da norma (parcela da realidade social apontada pelo texto/enunciado normativo, seus condicionantes factuais). (MÜLLER, 2009, p. 244).

5 Dessa maneira, Häberle demonstrou que a concretização normativa dos preceitos constitucionais não dependeria exclusivamente de um grupo privilegiado de juristas - juízes, promotores e advogados. (HÄBERLE, 1997).
} 
proposta é um aspecto de apelo político a uma sociedade pluralista e democrática que é imanente à sua teoria de interpretação constitucional . Segundo Häberle, uma das questões centrais do processo interpretativo diz respeito aos participantes desse processo.

Nesse diapasão, o autor estabelece que nos processos de interpretação da Constituição sejam considerados como determinantes para a sua consecução, todos os órgãos estatais, todos os poderes públicos e todos os cidadãos e grupos como agentes potencialmente envolvidos. (HÄBERLE, 1997).

A partir de tal configuração, o direito constitucional material apresentase como o resultado de uma multiplicidade de interesses e funções, o que conduz a uma diversidade prática de interpretação da Constituição como um aspecto irrenunciável na sua consecução.

Dessa maneira, não é subestimado o texto constitucional, nos moldes da velha hermenêutica, posto que, no primeiro plano do processo interpretativo encontra-se a chamada "esfera pública pluralista" 6 .

Frente ao aspecto eminentemente formal da esfera pública que caracterizou o Estado de Direito na sua configuração legalista, Häberle remete-se a uma concepção de Estado Constitucional, onde a Lei Maior não é apenas um conjunto de normas formais mas também é a expressão de certo estado de desenvolvimento cultural, tal como a representação de um dado povo, constituindo ele o espelhamento do seu próprio legado cultural e fundamento de suas aspirações e projetos de futuro. Trata assim a Constituição como um dado vivo cuja conformação determina-se em grande medida pelos intérpretes de uma sociedade aberta.

Ainda sob esse enfoque, a Constituição também reflete os aspectos básicos da expressão e transmissão cultural, o que a torna um canal idôneo para a reprodução e recepção de experiências culturais e soluções jurídicopolíticas.

Segundo Pérez Luño, é por essa razão que Häberle atribui tanta importância aos preâmbulos e simbologias constitucionais, tidos como sinais de identidade e elementos definidores de uma sociedade aberta sob a qual se constrói o Estado Constitucional. (PÉREZ LUÑO, 2007).

${ }_{6}$ Essa expressão liga-se à totalidade das forças pluralistas públicas, situadas no meio social e consideradas intérpretes potenciais da Constituição. (HÄBERLE, 1997). 


\section{OS APORTES TEÓRICOS DE RONALD DWORKIN COMO PRECURSOR DO NEOCONSTITUCIONALISMO}

$\mathrm{Na}$ realidade este debate europeu continental, teve como seu precursor o jus-filósofo norte-americano Ronald Dworkin, o qual, ainda na década de sessenta do século passado, lançou as bases conceituais para uma concepção de direito, crítica ao positivismo legalista, ao propor uma reaproximação entre Direito e Moral, a partir de princípios de moral política, vinculantes e determinantes para solução de hard cases, onde a insuficiência ou injustiça das normas jurídicas inviabilizassem uma íntegra solução de um dado caso.

Em linhas gerais pode-se dizer que Ronald Dworkin construiu as bases de sua filosofia do Direito a partir dos pilares da integridade e na indissolubilidade entre o Direito e a Moral. Os princípios, na teoria de Dworkin, assumem o papel fundamental de traduzir para o direito os valores intrínsecos àquela comunidade sob a qual impera. Esses princípios são, sempre, princípios morais, e, necessariamente, vinculados à justiça e à equidade (fairness). $\mathrm{O}$ eventual conflito entre os princípios será resolvido através de uma perspectiva notadamente pragmática.

$\mathrm{O}$ autor afirma que a política comum converge com a teoria política na busca pelos ideais de equidade, justiça e devido processo legal adjetivo, os quais deveriam constituir a base de ambições políticas de uma hipotética sociedade pré-política, onde os contratos seriam escritos numa "tábula rasa" e posteriormente instituídos como princípios da moral política daquela comunidade, ao ser instituída como comunidade política

Soma-se a esses princípios aquele considerado de essencial importância na teoria descrita: o direito à igualdade, considerada como o direito de cada cidadão ao tratamento com igual consideração e respeito. É a virtude da integridade política. O conceito de integridade, aliás, é peça-chave no entendimento da teoria de Dworkin. O próprio autor a conceitua como a exigência específica de moralidade política. (DWORKIN, 1999).

A integridade é dividida em dois âmbitos: integridade na legislação e integridade na deliberação judicial. (DWORKIN, 1999). Na legislação, a integridade corresponde à limitação dada ao legislativo e demais criadores do direito do que pode ser alvo de expansão ou criação, em termos de normas. Em outras palavras, é o dever daqueles que criam o direito através da legislação de mantê-lo coerente quanto aos princípios. De outra feita, encontra-se a deliberação judicial. 
Quanto a este segundo âmbito, a observância dos precedentes e necessária atualização do direito são requisitos à integridade de uma decisão. Aintegridade das decisões judiciais, por seu turno, poderia soar como a correspondente coerência dela em relação ao ordenamento em que está inserida. Mas é mais do que isso, pois exige uma construção que respeite e resguarde os valores tidos como essenciais à comunidade considerada e, igualmente, observe os precedentes, de modo a construir um sistema único e coerente de justiça e equidade.

A partir das manifestações do autor acerca dessa forma de integridade, verifica-se a preponderante importância que atribui ao Direito que se origina das decisões judiciais, que tampouco está dissociado da moral. A atividade jurisdicional levará em conta os princípios eleitos pela comunidade, a "ética comunitária", na busca pela decisão mais acertada. Através da construção de sua teoria política, e aliando-se nos princípios, o juiz sempre encontrará uma resposta correta.

Dworkin estipula o conceito de direito como integridade, momento construtor da dignidade humana a partir da integração de processos e fatores diversos que podem ser políticos, culturais, morais dentre outros. (DWORKIN, 2002).

\section{A CONSOLIDAÇÃO DO PARADIGMA NEOCONSTITUCIONAL}

A partir desses postulados e agora retomando o pensamento advindo do continente europeu, Robert Alexy $(1993,2001)$ construiu suas teses sobre princípios jusfundamentais, a partir de um viés analítico e sob uma metodologia baseada na ponderação axiológica, que, por sua vez, baseia-se numa teoria da argumentação jurídica como limite à discricionariedade do aplicador do direito, aspirando pela correção discursiva e racional de argumentos morais como base dos argumentos jurídicos.

Precisamente, a partir da teoria, chamada ponderacionista, de Alexy que elaborou um modelo quase lógico de "pesagem” axiológica de princípios jusfundamentais em colisão, visando decidir, em cada caso concreto, o princípio prevalente para afirmar um direito fundamental eventualmente lesado - formouse toda uma corrente de juristas e filósofos, notadamente da Itália e da Espanha a encampar o referido modelo teórico.

Nesse contexto, a Escola de Gênova, cunhou a expressão "Neoconstitucionalismo" ao designar um macroconceito que passou a abrigar 
teorias, por vezes divergentes, mas tendo um ponto de vista em comum: os direitos fundamentais possuem estrutura de princípios, sendo estes significativamente diversos das regras e sujeitos a colisões eventuais nas quais o intérprete julgador dos conflitos jurídicos, deverá ponderar os valores morais inscritos nos referidos princípios, obrigando o Judiciário a proceder, portanto, a uma interpretação moral da constituição.

A partir dessa guinada teórica propiciada pelo Neoconstitucionalismo e uma decorrente teoria da argumentação de fundamentação discursiva como a de Alexy (embora aqui outras teorias sejam relevantes, tais como as de Toulin, MacCormick e Atienza) é que se configuram as bases de um novo modelo jurídico a embasar uma nova realidade estatal: o Estado Constitucional de Direito. Neste novo contexto, as previsões constitucionais, antes enunciadas apenas em caráter formal e dependentes da prestação, amplamente discricionária, por parte do Poder Público (notadamente, o Poder Executivo) passaram a ser objeto de tutela jurisdicional. ${ }^{7}$

Esta seria uma das principais características do Estado Constitucional, e que, pelo advento do Estado Democrático de Direito, tornou-se seu ponto fulcral, na medida em que a própria Constituição passa a ser a forma privilegiada de se instrumentalizar a ação dos poderes públicos para a consecução dos desideratos do texto constitucional, compreendido na sua totalidade: dirigente e principiológico. (CANOTILHO, 1982). Em outras palavras, o Judiciário (sobretudo os Tribunais Constitucionais) passa a fazer parte eminentemente ativa da arena política - uma alternativa na conquista das promessas da modernidade. (STRECK, 1999).

\section{O SUBSTANCIALISMO COMO PROPOSTA INTERATIVAAO DEBATE NEOCONSTITUCIONAL}

Ante esta inexorável simbiose entre Direito, Moral e Política, cujo palco é o Poder Judiciário, assiste-se a uma proposta analítica de atuação judicial denominada "substancialismo", defendida, entre outros,por Ronald Dworkin e Mauro Cappelletti, e no Brasil, por autores como Paulo Bonavides, Ingo Wolfgang

${ }^{7} \mathrm{O}$ modelo de jurisdição constitucional de tipo concentrado, segundo o qual a tutela jurisdicional é acionada para guarda da Constituição, foi consagrado na Constituição da Áustria, de 1920, aperfeiçoando-se em 1929, quando se atribuiu ao Tribunal Constitucional o controle especializado e concentrado dos atos de governo e das leis. Este protagonismo do Tribunal Constitucional como guardião da Constituição foi obra de Hans Kelsen, quando de seu embate teórico com Carl Schmitt durante a República de Weimar, em 1931. (CADEMARTORI; DUARTE, 2009). 
Sarlet e Fábio Konder Comparato. Segundo a defesa de Cappelletti, o Judiciário pode incorporar ao sistema político grupos marginalizados, garantindo-lhes a oportunidade para a conquista de seus direitos e implementação de suas expectativas durante o processo judicial. (CAPPELLETTI, 1988a, 1988b). Esta concepção insere o Judiciário em novo âmbito das relações entre os Poderes de Estado, transcendendo a mera função de checks and balances. Muito além da harmonização e equilíbrio entre os Poderes, na tese substancialista o Judiciário assume o papel de intérprete constitucional "que põe em evidência, inclusive contra maiorias eventuais, a vontade geral implícita no direito positivo, especialmente nos textos constitucionais [...]" ${ }^{8}$. (STRECK, 1999, p. 43)

Sob outro patamar teórico (e também crítico quanto a algumas das teses centrais dos substancialistas) a teoria do Garantismo, entende que esta mudança opera um câmbio revolucionário de paradigma no Direito. Primeiramente, a condição de validade das leis não depende mais apenas das normas processuais sobre sua formação, mas, sobretudo, devem respeito às normas substantivas sobre seu conteúdo - ou seja, sua validade depende da coerência com os princípios de justiça estabelecidos na Constituição. Segundo, tem-se alterada a relação entre juiz e lei, bem como a natureza da função jurisdicional: enquanto no paradigma juspositivista havia a sujeição à letra da lei, qualquer que fosse seu conteúdo, agora se vê uma sujeição à Constituição, que impõe ao juiz a crítica diuturna das leis inválidas. Por fim, altera-se o papel da ciência jurídica, cuja função meramente analítica e descritiva passa a ser função crítica e construtiva em relação a seu objeto. ${ }^{9}$

\section{A NOVA HERMENÊUTICA NO CONTEXTO DO BRASIL}

Para Lenio Luiz Streck, no Brasil, ainda se está longe da postura substancialista, diante da inefetividade da expressiva maioria dos direitos sociais, "[...] além da falta de uma filtragem hermenêutico-constitucional das

\footnotetext{
${ }^{8} \mathrm{O}$ autor afirma que o garantismo de Luigi Ferrajoli se aproxima da abordagem substancialista, “[...] pelo valor que estabelece à Constituição, entendida em seu todo principiológico, e pela rejeição das posturas sistêmicas, através do que denomina de heteropoiese." (STRECK, 1999, p. 45). Segundo Ferrajoli, enquanto no passado o parlamento era onipotente em razão da política, sendo o direito mero produto e instrumento desta conjuntura, isto se altera a partir da guinada neoconstitucionalista, com o reconhecimento da Constituição como norma suprema, à qual todas as demais normas estão rigidamente vinculadas e subordinadas. (CADEMARTORI, 1998).

9 "Para Ferrajoli, a constitucionalização rígida dos direitos fundamentais - impondo obrigações e proibições aos poderes públicos - tem produzido efetivamente na democracia uma dimensão "substancial", que se acrescenta à tradicional dimensão "política", meramente "formal" ou "procedimental"”. (STRECK, 1999, p. 46).
} 
normas anteriores à Constituição [...]" (STRECK, 1999, p. 47). Isso se deve ao período compreendido entre 1964 e 1985, quando o país vivenciou uma ditadura militar propiciada por meio de um golpe de Estado que se sustentou mediante normas anômalas denominadas "atos institucionais". O denominado Estado Social não se realizou no país neste período, pois a função intervencionista do Estado, violenta sobremaneira, apenas serviu para aumentar as desigualdades sócio-econômicas e regionais. Enquanto na ditadura os direitos individuais e sociais eram constantemente vilipendiados e arrancados dos cidadãos, na transição democrática uma parcela mínima destes direitos vem sendo cumprida.

Não obstante, o controle abstrato das normas apresenta, segundo o autor, um déficit de eficácia, decorrente de uma baixa constitucionalidade, ou seja, quando os direitos e garantias fundamentais que apontam para o acesso à justiça permanecem ineficazes. Basta que se lembre do fato de que, muito embora o advento da Constituição Federal do Brasil de 1988 tenha inaugurado o período de transição democrática, apenas onze anos após sua promulgação foi regulamentado o instrumento de controle de constitucionalidade denominado arguição de descumprimento de preceito fundamental.

Ora, dentro do campo da dogmática constitucional brasileira, destacamse os modelos de hermenêutica constitucional que auxiliam as técnicas de decisão judicial pelos Tribunais Constitucionais. Todos estes instrumentos de controle abstrato (ou concentrado) da constitucionalidade norteiam-se por um conjunto de princípios interpretativos. ${ }^{10}$ Entretanto, este arcabouço hermenêutico (e esta série de instrumentos para o controle da constitucionalidade das leis) não impede(m) que autores como Gilberto Bercovici (2008) e Paulo Bonavides $(2004,2007)$ afirmem a ocorrência de decisões judiciais emanadas pelo Supremo Tribunal Federal que vão contra os desígnios da Constituição brasileira. Como conseqüência, identifica-se o esvaziamento de seus valores substanciais, o que representaria uma usurpação dos poderes constituintes. (STRECK, 1999).

Este panorama faz surgir uma série de questionamentos. Dentro de um Estado Democrático de Direito, qual seria a validade de uma hermenêutica jurídica que permitisse qualquer postura do intérprete/aplicador do Direito (neste caso, dos ministros do Supremo Tribunal Federal), ou, com Kelsen (1998), qual

\footnotetext{
${ }^{10}$ Tais como o da unidade da Constituição; do efeito integrador; da máxima efetividade ou eficiência; da justeza ou conformidade funcional; da concordância prática ou harmonização; e, principalmente, da força normativa da Constituição. Assim, diante de uma norma plurissignificativa, deverá o intérprete/aplicador julgá-la sempre utilizando-se da técnica de Interpretação Conforme a Constituição. (CADEMARTORI; DUARTE, 2009, p. 34-35).
} 
seria a validade de uma interpretação/decisão judicial que fosse apenas um ato de vontade? Qual o perigo em se admitir que o Direito seja aquilo que o intérprete/ aplicador diz que é? ${ }^{11}$ Neste aparente relativismo, como se falar em efetividade do controle constitucional, como medida para concreção normativa de direitos fundamentais?

Diante destas questões, Streck chega a afirmar que, a despeito da subjetividade do intérprete-aplicador do direito, pode-se balizar uma decisão judicial de acordo com a sua correção: a resposta correta, dada pelo intérpreteaplicador, é aquela adequada à Constituição. Faltando a esta decisão judicial uma fundamentação que a vincule adequadamente à Constituição, estar-se-á diante da negação de um direito fundamental do cidadão, qual seja, o direito fundamental de assistir a criação do Direito segundo os postulados constitucionais. A resposta adequada à Constituição é aquela que deve ser confirmada na própria Constituição, na Constituição mesma.

\section{INSUFICIENCIA DAS PROPOSTAS NEOCONSTITUCIO- NALISTAS A PARTIR DO DIREITO INSURGENTE E DESOBEDIENTE BRASILEIRO}

Parte-se agora de alguns caracteres gerais do Neoconstitucionalismo, tomando-se ele como convergência de variadas tendências teóricas, ou seja, como um ideário, um conjunto de aspirações comuns expostas por autores diversos, sem sistematização ulterior. Dentre estes caracteres, destacam-se como principais:

a) a concepção de Estado como Estado Constitucional, e não Estado de Direito na sua acepção típica do século XIX, onde o limite de todo direito estava na lei stricto sensu, e não na Constituição, apontando assim, no Estado Constitucional, a supremacia valorativa e normativa da Constituição frente a todo direito infraconstitucional, que com ela deve se coadunar, não de maneira meramente formal, conforme requisitos de procedimento e competências previstos na Constituição, mas acima de tudo, de maneira substancial, é dizer, a

\footnotetext{
${ }^{11}$ Como sustenta Streck, admitir as condições do modo próprio de ser-no-mundo de cada pessoa, ou seja, aceitar o fato de que os sujeitos que são intérpretes-aplicadores do direito possuam suas preferências pessoais, seus valores, suas intuições, etc., não necessariamente implica dizer que não haja condições de verificação sobre a correição ou veracidade acerca de cada decisão que este sujeito tomar. Em outras palavras, o significado do texto normativo a ser interpretado-aplicado não advém tão somente do conjunto linguístico do "próprio texto", mas compõe-se da integração entre decisões anteriores, aplicação coerente destas decisões e da compatibilidade do texto com a Constituição. (STRECK, 1999).
} 
normatividade infraconstitucional deve se adequar e vincular ao conteúdo e aos valores constitucionalmente positivados;

b) a constitucionalização do direito, que se articula a partir do primeiro caráter: a Constituição passa a ser o ponto de articulação jurídico-político entre o ordenamento jurídico e o Estado, não mais encarados como ser análogo como estipulou Kelsen (1999);

c) atrelar a Moral ao Direito, aproximando-o de anseios de um tipo de Justiça, nos moldes iluministas, fazendo assim com que convirjam os discursos jurídico e moral, sendo imbricados também as argumentações de cunho moral com as de cunho jurídico. Esta retomada moral se deve ao fato da necessidade de solução do que Hart e Dworkin concordaram ser hard cases;

d) graças à obra de Dworkin, os princípios adquirem normatividade, é dizer, não mais carecem de eficácia por serem meros programas, mas, ao contrário, possuem aplicação direta e demandam uma eficácia plena, já que consubstanciam o sustentáculo vertebral, estrutural e valorativo dos direitos e garantias fundamentais, que, neste interregno, também adquirem importância preponderante;

e) o texto legal não mais é confundido com norma. Anorma se concretiza apenas quando ao texto legal é conferido um sentido específico a partir de sua interpretação-aplicação.

A concepção aberta e plural do princípio, impressa por Dworkin, aproximase à nova realidade constitucional latino-americana; mas nossa necessidade não se encerra nesta possibilidade. A positivação dos princípios, o caráter normativo da principiologia, a aproximação umbilical entre o discurso jurídico e o discurso moral, a fundamentação do ordenamento num valor de justiça constitucionalmente assegurado e sistematizado, todas estas conquistas neoconstitucionais ainda orbitam na organização/administração sociopolítica do Estado para se operacionalizar.

Há exceções, como a proposta conjunta de Peter Häberle e, no passado, de Konrad Hesse. Este último falava de uma força normativa intrínseca ao texto Constitucional, que adquiria vida na medida em que participava da ordenação normativa das relações do mundo da vida. Assim, dizia Hesse, no choque fático das relações de poder de uma dada sociedade, deve preponderar, como de fato prepondera, a vontade da Constituição e a vontade de Constituição, representada pela atitude de seus intérpretes. (HESSE, 1991).

Peter Häberle, não obstante, vai afirmar uma sociedade aberta dos livres intérpretes da Constituição, postulando que todo cidadão é um potencial intérprete- 
aplicador dos ditames e valores constitucionais. Häberle foi pioneiro no sentido de retirar a maior relevância dos juristas na criação do direito, aplicando conscientemente um princípio igualitarista. No entanto, deve-se lembrar que a teoria de Häberle é de matiz liberal e, portanto, pressupõe que os cidadãos podem exercer, por si mesmos, sua cidadania, partindo de dois pressupostos praticamente impensáveis numa realidade latino-americana: primeiro, que todos os cidadãos conhecem a Constituição e estão aptos a interpretá-la; segundo, que todos os cidadãos conhecem os mecanismos, instrumentos e procedimentos para viabilizar essa concretização normativa do direito a partir da interpretaçãoaplicação. (HABERLE, 1997).

A partir do pensamento desses juristas, se poderia articular uma participação ampla e irrestrita da sociedade aberta dos livres intérpretes constitucionais na interpretação "verdadeira" e original da força normativa da Constituição. Nesta perspectiva, estão potencialmente envolvidos na interpretação constitucional todos os cidadãos.

Mas, numa nação como a brasileira, esta fórmula resulta pouco eficiente. Com efeito, contextualizando o pensamento destes dois alemães, percebe-se que o lugar do qual seu discurso é emitido é um lugar de pouca miscigenação étnico-cultural se comparado ao brasileiro.

Em sentido inverso à concepção tradicional, o constitucionalismo popular apregoa a ideia de que o controle judicial da lei e da Constituição é um processo contínuo e permanente, que pela própria demanda democrática e constitucional, jamais deve ter fim. Assim, o controle judicial da Constituição inscreve-se num processo maior, qual seja, o processo constituinte. Este processo constituinte não se encerra na emissão do texto Constitucional, mas se operacionaliza durante toda a disputa no seio da sociedade civil pela impressão de sentidos ao texto.

Ou seja, o processo constituinte é permanente porque todos os cidadãos estão legitimados a interpretar-aplicar a Constituição, ou seja, extrair de seu texto um sentido semântico que lhe gere caráter de normatividade. Aqui a ideia de Friedrich Müller (1991) é retomada, quando o texto legal é tomado como programa da norma, dependendo do âmbito da norma, suas condições fáticas de aplicação e interpretação, para se tornar, efetivamente, um mandamento normativo.

E as propostas para exercer esse comunitarismo interpretativo de maneira concreta são diversas: elegibilidade dos membros do Poder Judiciário; redução de seus mandatos eletivos para períodos curtos; promoção de membros representativos de classe para fazerem pressão política aos juristas da Corte 
Constitucional e, em última instância, em casos extremos, o desafio direto, qual seja, a desobediência coletiva e organizada: a negação de obediência aos mandamentos deste Poder Judiciário, desde que careçam de valor moral e legitimidade política no seio do tecido social.

\section{O ESTATUTO DAS CONSTITUIÇÕES LATINO AMERICANAS SOB A PERSPECTIVA DO GARANTISMO}

Luigi Ferrajoli (2010), a partir da sua matriz garantista, afirma que as Constituições do Brasil (1988), do Equador (2008) e da Bolívia (2009) operam uma revolução paradigmática no Constitucionalismo, inaugurando uma nova fase do constitucionalismo democrático. Muito em razão da ampla positivação dos direitos sociais: tal processo alteraria radicalmente o papel atribuído à Administração Pública, sendo necessário repensar a estrutura institucional do aparelho burocrático estatal. Segundo o jurista italiano, os direitos sociais descansam na "esfera do indecidível", situação na qual nenhuma maioria pode validamente decidir. Isto significa que esta esfera dos direitos fundamentais (os direitos sociais) será imposta enquanto programa democrático-constitucional (sendo normas de aplicação imediata) contra maiorias eventuais que contra ela se prostrem. É um terreno tipicamente garantista.

Daí porque Ferrajoli (2010) separa duas dimensões nas quais poderiam se articular a democracia constitucional: a dimensão afeta à discricionariedade política, relacionada às funções e instituições de governo; e a dimensão jusfundamental da esfera do indecidível, com as respectivas funções e instituições de garantia. Assim é que, a partir de algumas críticas do garantismo, à corrente oposta, o neoconstitucionalismo, pode-se esclarecer algumas situações do direito brasileiro e de seu constitucionalismo que demandam situar na sua devida dimensão, as caracterizações de Ferrajoli, quanto à terceira geração de Constituições, é dizer, as constituições latino americanas. Seus elogios e os caracteres de qualidade apontados, tais como: a) mais forte rigidez; b) mais amplo catálogo de direitos; c) vínculos orçamentários em matéria de direitos sociais; d) controle de constitucionalidade por omissão; e) um Ministério Público instituído para defesa dos direitos fundamentais; f) a defesa pública ao lado da acusação pública; g) as instituições de garantia dos direitos políticos; demandam uma análise sob um ponto de vista externo ao direito, nos termos, a seguir explicitados, quando analisa a situação sócio-política dos brasileiros e de seu direito insurgente e desobediente. 
Luiz Henrique Urquhart Cademartori; Priscilla Camargo Santos e Rodrigo Adriano Faresin

\section{ASPECTOS CRÍTICOS DO NEOCONSTITUCIONALISMO SEGUNDO A TEORIA DO GARANTISMO}

Em linhas gerais, pode-se descrever as teses centrais que embasam a crítica do Garantismo ao Neoconstitucionalismo, partindo-se da premissa de que, ao contrário desta última corrente teórica, o Garantismo não pretende separar-se, cingir, ou superar o Positivismo Jurídico, substituindo sua matriz epistemológica por outra de caráter jurídico-moral. Pelo contrário, afirma sua teoria sob bases positivistas, porém, reforçando suas teses centrais e corrigindo distorções oriundas da sua primeira versão, chamada por Ferrajoli (2010) de "paleopositivismo". A rigor, pode-se identificar no Garantismo, segundo Gascón de Abellán, como seus traços mais característicos, uma dupla divergência nos planos do "Dever Ser" e do "Ser" do Direito. A primeira delas se configuraria entre o chamado "dever ser externo" ou ético-político do Direito e o "ser" dos sistemas jurídicos no seu conjunto, o que em verdade revela a clássica separação entre Direito e Moral, vale dizer, entre Justiça e Validade, ou entre Legitimidade Externa e Legitimidade Interna.

Agora, tais distinções, não implicam afirmar que o Direito não incorpore valores ou princípios morais, ou não tenha certa relação conceitual necessária com a moral. Neste caso, Ferrajoli (2010) apenas constata que todo sistema jurídico expressa a moral ou as morais dos seus legisladores, e aqui concorda com a tese de Alexy de que todo direito parte sempre de uma "pretensão de correção". Entretanto, o ponto de divergência de Ferrajoli se baseia no fato de que as constatações acima sobre as implicações entre o Direito e a Moral levam a duas conclusões básicas: a) a moralidade (ou justiça) de uma norma não implica a sua necessária juridicidade (ou validade, ou ainda, seu pertencimento ao um dado ordenamento jurídico). B) A juridicidade (validade ou pertencimento ao um sistema jurídico) de uma norma não implica a sua moralidade ou justiça.

A negação da primeira tese constitui o substrato do Jusnaturalismo Clássico. Já, a negação da segunda tese apresenta uma tese ambivalente, vale dizer, expressa um postulado jusnaturalista ao se assumir uma noção substancial e meta-jurídica de juridicidade ou validade, enunciando uma confusão entre tais esferas como o faz Alexy, ao afirmar que uma norma perde sua validade jurídica quanto se apresenta como extremadamente injusta. Ao contrário de tais remissões jusnaturalistas, uma tese ético-legalista como a de Ferrajoli (2010), expressa a ideia de que as normas jurídicas possuem sempre algum valor moral, independente do seu conteúdo, no caso de que se assuma uma noção formal e 
puramente intra-jurídica de juridicidade, ou validade, sendo este o critério central de interpretação das normas e não o apelo imediato a valores de justiça.

A segunda divergência entre o "Ser" e o "Dever-Ser" apontada como central para definir a proposta Garantista, revela-se ainda mais importante, introduzida pela positivação, nas atuais constituições rígidas, das condições substanciais de validade das leis, que são os direitos fundamentais, operando-se na diferenciação entre validade e vigência, ou seja, entre o "dever ser interno" (no Direito) e o "Ser" das normas legais. Ambos os juízos requerem critérios, também jurídicos (no caso do "Ser") e não apenas fáticos e, de outra parte, apenas jurídicos (no caso do "Dever Ser"), pois ambos se remetem à interpretação sobre produção infraconstitucional de leis e sua conformidade com a Constituição, nos âmbitos procedimental (vigência), além de substancial ou material, quanto à observância dos direitos fundamentais (validade).

Finalmente, soma-se às divergências antes apontadas, uma terceira, referente à banal diferença entre direito e realidade, ou normatividade e efetividade, entre normas e fatos, em suma, entre o "Dever Ser" jurídico (ou de direito) e a experiência jurídica concreta, vinculada, não mais ao caráter descritivo, mas normativo do direito, com respeito às condutas reguladas, incluindo-se aqui, o funcionamento real das instituições e seus aparatos de poder.

Consideradas essas razões, cumpre apontar, na realidade jurídicoinstitucional brasileira, quais as defasagens mais importantes que se verificam entre a realidade política e jurídica - vale dizer no âmbito do Ser do Direito praticado - do país frente à sua previsão dogmática, inerente ao mundo do Dever-Ser constitucional do Brasil.

\section{A CONSTITUIÇÃO DO BRASIL E SUAS PRÁTICAS INSTITUCIONAIS: INCOMPATIBILIDADES NOS PLANOS DO SER E DEVER SER}

Relativamente ao conjunto de caracteres levantados por Ferrajoli (2010), de Constituições de Terceira Geração, tais como a brasileira podem ser referenciadas as seguintes discrepâncias entre suas prescrições dogmáticas e sua realidade institucional:

a) a maior rigidez da nossa Constituição Federal é relativizada quanto à situação das medidas provisórias, das emendas constitucionais e o conhecido "contrabando normativo", quando alterações legislativas são realizadas por uma das Casas Legislativas do Congresso Nacional brasileiro (seja o Senado, seja a Câmera dos Deputados), sem, no entanto, passarem sob o crivo analítico da 
outra casa, o que é norma expressa do processo legislativo brasileiro. As hipóteses para tal tráfico de influência são inúmeras: negociatas políticas, troca de votos, nepotismo, favoritismos, clientelismo;

b) um maior amplo catálogo de direitos positivados, por si só, ainda demanda esforços legislativos, muitas vezes inertes, para assegurar sua aplicação imediata. Dependentes de uma Administração Pública, por vezes, amortizada, e de um Judiciário de pouca eficiência, os cidadãos brasileiros garantem a concretização de seus direitos fundamentais pela desobediência e emergência de lutas como a dos movimentos sociais organizados;

c) os vínculos orçamentários em matéria de direitos sociais são muitas vezes burlados pelo tráfico de influência no Congresso Nacional (Poder Legislativo), sofrendo "contrabando normativo" como declinado acima;

d) o controle de constitucionalidade em geral, e a problemática da tutela jurisdicional como arena central da disputa política já foi abordado anteriormente, dando como resultado da inércia do Poder Legislativo duas situações anômalas no sistema democrático: a hipertrofia do Poder Executivo e o ativismo judicial, duas posturas de subtração da prerrogativa legiferante do órgão legislativo clássico;

e) o Ministério Público brasileiro vem sofrendo transformação estrutural e institucional desde o início da década de 80 . No entanto, nem todos seus integrantes assumiram a nova postura garantidora dos direitos fundamentais, estando ainda adstritos ao conservadorismo retrógrado da época ditatorial, quando o Ministério Público funcionava como polícia do Executivo e atuava meramente como acusador público;

f) as instituições de garantia dos direitos políticos são meras gestoras eleitorais: regulam unicamente os processos eleitorais partidários, excluindo desse processo de disputa política os movimentos sociais legitimamente estabelecidos, a cidadania difusa de todos os cidadãos brasileiros e os índices de analfabetismo que ainda assolam toda a Federação.

\section{CONSIDERAÇÕES FINAIS}

Consideradas todas essas digressões, a respeito das recentes teorias jurídicas oriundas, tanto da Europa como dos Estados Unidos, e o grau de recepção que poderiam, ou efetivamente tiveram perante o panorama teórico e institucional de países da América Latina, tais como o Brasil, algumas considerações são fundamentais. De uma parte, entende-se não ser possível uma rejeição taxativa e de caráter absoluto de tais teorias externas, pautada 
por juízos de cunho culturalmente xenófobos, o que confere a esse tipo de negação um estatuto inequivocamente irracional, até porque toda experiência cultural torna-se, sempre, desenraizada.

Assim, tampouco a sua aceitação acrítica e fora de quaisquer parâmetros contextuais, pois culturas como a brasileira, assim como quaisquer outras, possuem também suas idiossincrasias e especificidades próprias que são peculiares apenas a elas e isto, obviamente, demandará sempre uma adequada filtragem interna a toda e qualquer experiência exterior que porventura possa ser considerada benéfica.

De todo modo, a pura antropofagia cultural, tão decantada pelos modernistas brasileiros da década de vinte do século passado, de apenas digerir o que vem de fora e produzir a partir disso, uma síntese local, hoje cede mais espaço a formulações teóricas próprias e propostas de saídas políticas e jurídicas no plano institucional e notadamente constitucional, que podem ser exemplos para outras culturas, mesmo a dos países centrais, apesar de todos os atuais entraves que a realidade conjuntural de países como o Brasil ainda apresentam.

De fato, países como o Brasil, com a diversidade cultural e étnica que apresentam, não poderiam, sob o risco de tentações autoritárias e/ou absolutistas, forjar uma identidade unidimensional, falando em nome de valores essencialmente indígenas, negros, europeus ou da índole que seja como discurso único a pautar um tipo específico de cultura que na realidade não existe como um dado totalmente homogêneo. Mesmo que se queira falar em mestiçagem, como fenômeno inerente às culturas latinas como a brasileira, também ela se apresenta como mistura de diversas etnias entre diversos indivíduos a formar diversos mestiços.

A diferença que se percebe hoje é que agora, não mais se olha desde a América Latina para fora, tentando copiar ou absorver alguma nova experiência teórica, cultural ou institucional, que seja entregue por europeus e norteamericanos, um olhar uni-direcionado que apenas percebe e adapta as informações exteriores e nada tem para ofertar em troca. Desta vez, os olhares externos se voltam para cá, buscando saídas para os problemas alienígenas e curiosos para entender as novas formas que possam ser forjadas em nível local, para dar conta dos atuais desafios políticos e jurídicos que se enfrentam no mundo todo.

Nesse contexto, é que autores estrangeiros como Ferrajoli, constatam as diferenças e novos aportes político-jurídicos que constituições, como a brasileira trazem de novo para fazer frente a suas conjunturas atuais e futuras. Embora seja assim, e conforme já se mostrou, ainda há muito a ser aperfeiçoado, mais 
do que na dogmática constitucional brasileira, nas práticas efetivas dos agentes do Estado encarregados pelo seu zelo e consecução.

Com efeito, desde sua promulgação, a Constituição brasileira de 1988 rompendo um longo hiato de ditadura militar, dentre tantos sobressaltos golpistas perpetuados ao longo da sua história republicana - tornou-se objeto de inúmeras tentativas de supressão dos seus avanços sociais plasmados nos direitos fundamentais, bem como críticas quanto ao seu suposto detalhismo normativo.

Somando-se a isto, não faltaram questionamentos oriundos de ambas as direções ideológicas, como sendo demasiado conservadora, por alguns setores da esquerda, ou excessivamente socializante, por parte de setores liberais ortodoxos de direita, na sua versão nacional. Enfim, economicamente, interventiva, de um lado, ou protetora da livre iniciativa em amplo espectro, por outro, segundo as análises de uma ou outra corrente de pensamento, a nossa Constituição prevaleceu ao longo destas duas décadas como o referencial institucional, por excelência, a orientar toda a trajetória de lutas e avanços sociais dos brasileiros. Quanto aos seus atuais entraves, o caminho está aberto a todas as novas experiências.

\section{REFERÊNCIAS}

ALEXY, Robert. Teoria de losderechos fundamentales. Madri: Centro de Estudios Constitucionales, 1993.

. Teoria da argumentação jurídica. São Paulo: Landy, 2001.

ARRUDA JUNIOR, Edmundo Lima; GONÇALVES, Marcos F.

Fundamentação ética e hermenêutica: alternativas para o direito.

Florianópolis: CESUSC, 2002. p. 189-195.

BERCOVICI, Gilberto. Soberania e constituição: para uma crítica do constitucionalismo. São Paulo: QuartierLatin, 2008.

. A problemática da constituição dirigente: algumas considerações sobre o caso brasileiro. Revista de Informação Legislativa, Brasília, ano 36, n. 142, abr./jun. 1999.

BONAVIDES, Paulo. Curso de direito constitucional. 15. ed. São Paulo: Malheiros Editores, 2004. 
2007.

. Do estado liberal ao estado social. 8. ed. São Paulo: Malheiros,

CADEMARTORI, Luiz Henrique; DUARTE, Francisco Carlos. Hermenêutica e argumentação neoconstitucional. São Paulo: Atlas, 2009.

CADEMARTORI, Sérgio Urquhart. Estado de direito e legitimidade: uma abordagem garantista. Porto Alegre: Livraria do Advogado, 1998.

CANOTILHO, José Joaquim Gomes. Constituição dirigente e vinculação do legislador. Coimbra: Coimbra Editora, 1982.

CAPPELlETTI, Mauro. Acesso a justiça. Tradução de Ellen Gracie Northfleet. Porto Alegre. Sergio Antonio Fabris Editor, 1988a.

. Juízes legisladores?Porto Alegre: Sergio Antonio Fabris, 1988b.

DWORKIN. Ronald. Levando os direitos a sério. Tradução de Nelson Boeira. São Paulo: Martins Fontes, 2002.

. O império do direito. São Paulo: Martins Fontes, 1999.

FERRAJOLI, Luigi. Jueces y política. Derechos y libertades. Revista del Instituto Bartolomé de las Casas, Madrid, ano 4, n. 7, 1999.

. Direito e razão: teoria do garantismo penal. 2. ed. São Paulo: Editora RT, 2010.

HÄBERLE, Peter. Hermenêutica constitucional: a sociedade aberta dos intérpretes da Constituição: contribuição para a interpretação pluralista e "procedimental" da Constituição. Tradução de Gilmar Ferreira Mendes. Porto Alegre: Sergio Antonio Fabris, 1997.

HABERMAS, Jürgen. Direito e democracia: entre facticidade e validade. Tradução de Flávio Siebeneichler. Rio de Janeiro: Tempo Brasileiro, 1997. v. 2.

HART, Herbert. O conceito de direito. 6. ed. Tradução de Armindo Ribeiro Mendes. Lisboa: Fundação CalousteGulbenkian, 2011. 
HESSE, Konrad. A força normativa da constituição. 2. ed. Tradução de Gilmar Ferreira Mendes. Porto Alegre: Sergio Antonio Fabris, 1991.

KELSEN, Hans. O que é justiça? a justiça, o direito e a política no espelho da ciência. Tradução de Luis Carlos Borges. São Paulo: Martins Fontes, 1998.

. Teoria pura do direito. Tradução de João Baptista Machado. 6 . ed. São Paulo: Martins Fontes, 1999.

LASSALLE, Ferdinand. Que é uma constituição? Porto Alegre: Villa Martha, 1980.

MÜLLER, Friedrich. A força normativa da constituição. 2. ed. Tradução de Gilmar Ferreira Mendes. Porto Alegre: Sergio Antonio Fabris, 1991.

. Teoria estruturante do direito. Tradução de Peter Naumann e Eurides Avance de Souza. 2. ed. São Paulo: Ed. Revista dos Tribunais, 2009.

. Métodos de trabalho do direito constitucional. São Paulo: Max Limonad, 2000.

NEVES, Marcelo. A constitucionalização simbólica. São Paulo: WMF Martins Fontes, 2007.

PÉREZ LUÑO, Antonio Enrique. La universalidad de los derechos humanos y el Estado constitucional. Colômbia: Universidad Externado de Colombia, 2007.

STRECK, Lenio Luiz. Hermenêutica jurídica e(m) crise: uma exploração hermenêutica da construção do direito. Porto Alegre: Livraria do Advogado, 1999.

Submetido em 19/08/2015 Aprovado em 25/10/2015

Como citar: CADEMARTORI, Luiz Henrique Urquhart; SANTOS, Priscilla Camargo; FARESIN, Rodrigo Adriano. A constituição brasileira como produto de terceira geração: convergências e divergências entre o constitucionalismo latino americano e a teoria do garantismo jurídico. Scientia Iuris, Londrina, v.19, n.2, p.9-32, dez. 2015. DOI: 10.5433/21788189.2015v19n2p9. ISSN 2178-8189. 